\title{
Impact of a One Day Crisis Resource Management Training on the Work Satisfaction among Emergency Department Healthcare Staff
}

\author{
Teodora Sorana Truta ${ }^{1}$, Irina Ban²*, Cristian Boeriu ${ }^{1}$, Marius Petrisor ${ }^{1}$, Diana Aniela Moldovan ${ }^{3}$, Sanda \\ Maria Copotoiu ${ }^{1}$
}

1. University of Medicine and Pharmacy Tirgu-Mures, Romania

2. Universita degli Studi di Padova Dipartimento di Medicina Padova, Italy

3. Tirgu-Mures Emergency Clinical County Hospital, Tirgu Mures, Romania

\begin{abstract}
Objective: To evaluate the impact of a single day Crisis Resource Management (CRM) oriented team training, combining didactic and simulation sessions, on work satisfaction of the healthcare staff working in an Emergency Department. Methods: Seventy health professionals with different qualifications, working in an emergency department, were enrolled in the study. After enrollment, participants were asked to complete a work satisfaction questionnaire and to choose a day for the training session according to their availability. Each training session took place in the simulation center and consisted of several elements: didactic session and simulation session, followed by instructor facilitated debriefing. The lecture was focused on medical errors and CRM principles. Two months after, they were asked to complete again the work satisfaction questionnaire. Results: There were no significant improvements on the items evaluated through the work satisfaction questionnaire for none of the professional categories involved, except for 'the possibility to refer the patient to a specialist whenever was considered necessary' for the doctors. Improvements were seen for the same professional category on the following items: workload, leisure time, level of stress at work, time and energy spent on administrative tasks. Conclusions: The findings of this study do not support the effectiveness of a single day CRM training as a tool to improve the work satisfaction among medical staff in ED. Further research is necessary.
\end{abstract}

Keywords: work satisfaction, crisis resource management, training

Received 3 August 2018 / Accepted 27 August 2018

\section{Introduction}

Burnout and job dissatisfaction among healthcare staff working in EDs are not rare. Among all specialties, emergency medicine has the highest levels of physician burnout of over $60 \%[1,2]$. Job satisfaction varies between countries, being reported as $65.2 \%$ in USA [3], 50-60\% in Japan [4], 24.3\% in Hong Kong [5]. As job satisfaction acts as a key factor on the individual's and organization's performance and is related to the quality of the provided services [6], efforts to improve it are necessary.

Emergency Department (ED) environments are characterized by difficult working conditions, some of which seem to be common to various clinical settings, independent of the geographical, social and cultural conditions: frequent staff member substitutions, multiple handovers, high workloads and high-risk cases, overcrowding and an increasing access block of the patients are just some of the elements frequently described in literature. Of these factors, ineffective inter-professional communication between healthcare providers seems to lead to fragmentation of the care delivery process, work duplication and problems during handover [7]. All these factors make the ED a place very prone to errors, and an inverse relationship between medical errors and job satisfaction among physicians and nurses has been reported $[8,9,10]$.

* Correspondence to: Irina Ban

E-mail: bercan.irina@gmail.com
As human factors were accounted to be responsible for up to $90 \%$ of the accidents in the workplace [11], a training towards improving human factors seems reasonable. With this aim, Crisis Resource Management (CRM) training has been developed by the aviation industry, being responsible for the decreased number of aircraft accidents in the last four decades [12], and then translated into the high-risk areas in medicine, as anesthesia, intensive care and emergency medicine.

CRM primary objectives are to improve team dynamics, to identify and to help changing mental models that create barriers in adopting effective communication, effective task management, healthy leadership behaviors and to increase awareness. [13].

Promising results on errors reduction and performance improvement in ED, through a formal teamwork training, were reported by Morey et al [14].

It would be intuitive to assume that an educational intervention aimed at improving communication, team dynamics and reducing errors would lead to an indirect and at least partial improvement in work satisfaction scores.

However, few data are available regarding the impact of this type of training on the general work satisfaction and even less information specifically linked to the impact of simulation-based educational interventions.

This study is aimed to assess whether a single day CRM oriented team training combining didactic and simulation sessions can improve work satisfaction among the medical staff working in an Emergency Department. 


\section{Methods \\ Study design}

This study is a part of a larger prospective interventional study assessing the impact of a single day CRM oriented training on technical and nontechnical skills of medical staff working in the ED.

Our study was conducted in the Tirgu-Mures Emergency Clinical County Hospital, Romania. The hospital has a five-year emergency medicine residency training program as well as an affiliated simulation center dedicated to multidisciplinary and inter-professional training in emergency and disaster medicine. The annual census of this emergency department is approximately 77,000 patients of whom around $10 \%$ are critical patients.

All medical staff without prior CRM training, excluding first-year emergency medicine residents with less than three months experience in ED, were invited to participate.

Seventy staff members volunteered for this study between March and July 2016: 20 emergency medicine attending physicians, 10 emergency medicine residents, and 40 nurses.

The study protocol was approved by the Ethics Committee of the Tirgu-Mures Emergency Clinical County Hospital and informed consent was obtained from all participants.

After enrollment, participants were asked to complete a work satisfaction questionnaire (Figure 1). The questionnaire was anonymous. We established a period of ten days dedicated to training sessions. The participants were invited to choose a day for the training session according to their availability. The training sessions took place in the simulation center, where we reproduced the ED's resuscitation room conditions. Each training session lasted one day (6 to 7 hours) and consisted of several elements. Initially participants received a lecture focused on medical errors and CRM principles (Figure 2). The role of human factors in errors' occurrence was emphasized as well as the role of CRM training in averting their appearance or mitigating their effects. After the lecture, but before starting the simulation scenarios, participants had the opportunity to familiarize themselves with the manikin and the simulation setting.

For each session, we had two interprofessional teams consisting of one attending physician, one resident and two nurses. We ran six scenarios representing critical patients (four medical cases and two trauma cases). One team ran through a scenario while the other team observed the exercise from a remote room via a high-resolution real time video transmission system. Each team was exposed to all cases, participating actively in three scenarios and being observers for the other three.

The simulation was run by two instructors with CRM background training (one doctor and one nurse) and an IT technician. Each scenario was followed by an instructor facilitated debriefing. Both technical and non-technical issues relating to team performance and team work were discussed, all clinical errors were addressed either by the participants or by the instructors. Both teams were involved in each debriefing, but the active participants had priority in providing feedback. All the participants were encouraged to speak up regardless of their profession (doctor or nurse) and experience.

Two months after this training session, the participants were asked to complete again the work satisfaction questionnaire.

The questionnaire used in this study was designed to measure the work satisfaction among physicians and was validated by Bovier $\mathrm{P}$ and Perneger $\mathrm{T}$, being published in 2003. [15].

The questionnaire was translated from French to Romanian by one of the authors of this study (TS) and from Romanian to French by a native French speaker (DF).

The questionnaire has five domains of satisfaction with one to four items: patient care, work-related burden, income-prestige, personal-rewards and relations with colleagues (Figure 1 and 2).

The item "the way you are currently paid (fee-for-service, salary, capitation, etc.) was removed from the original questionnaire as it was not applicable in our situation (all the participants being employees and receiving a salary).

The item "Your professional relations and interactions with other medical doctors" was divided in two: relations with doctors from the ED and with doctors from other

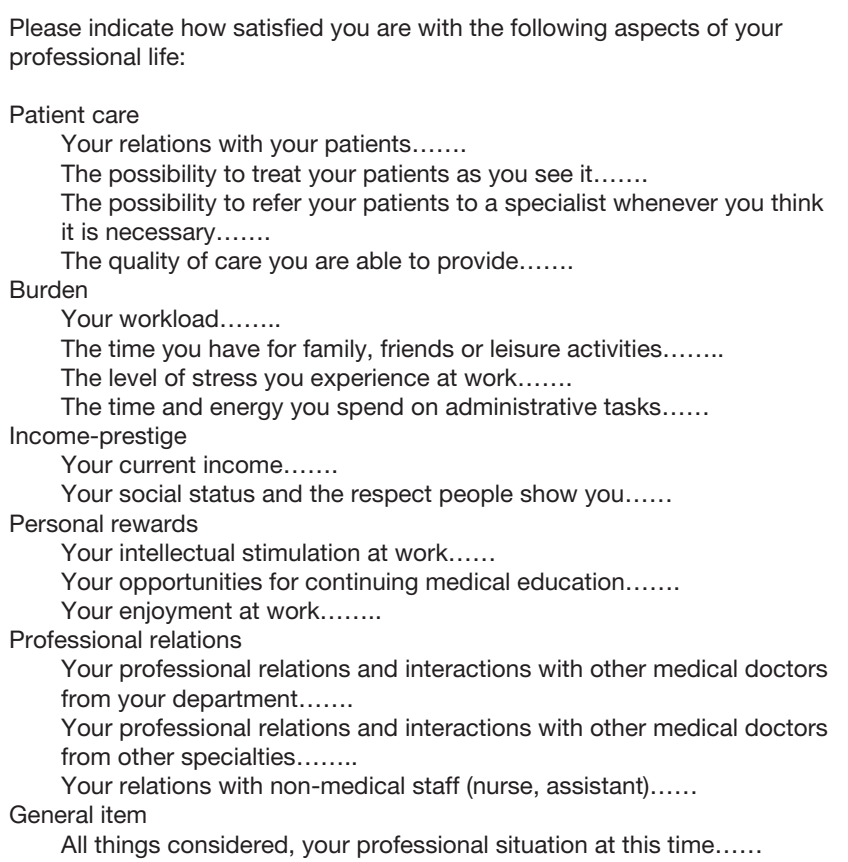

Fig. 1. Work satisfaction questionnaire

Know your environment (location and function of equipment, human resources and the level of experience, cultural environment) Anticipate, share and review the plan

Ensure leadership and role clarity

Communicate effectively

Call for help early

Allocate attention wisely- avoid fixation

Distribute the workload- monitor and support team members

Fig. 2. CRM key principles according based on the work of Gaba and Salas, modified by Carne [15] 
specialties, as interaction with others specialist doctors who don't understand the functioning of the ED might be a reason of dissatisfaction for the medical staff working in ED.

Participants were asked to rate their satisfaction degree for each item, using a 7-points Likert scale, 1 being extremely dissatisfied and 7 being extremely satisfied.

\section{Statistical analysis}

All data were collected in a Microsoft Excel Spreadsheet, independently for doctors and nurses. Graph Pad Prisma 5 and Microsoft Excel programs were used to analyze the data. The normality test used was D'Agostino.

This analysis revealed that the data series were nongaussian, with skewed distribution curves. Next statistical analysis tests were performed considering the fact that our data were non-gaussian, therefore median and interquartile range (IQR) were used to describe each data series, and Wilcoxon signed-rank test to assess the statistical significance for central tendency difference. The significance level used in all statistical tests was 0.05 .

\section{Results}

Seventy participants were enrolled in the study (30 doctors: 20 attending physicians and 10 residents, representing $94 \%$ of the total numbers of doctors without previous CRM training and 40 nurses, representing 69\% of the total number of nurses without previous CRM training). Sixty-three completed the study. Seven participants (2 doctors and 5 nurses) didn't complete the questionnaire two month after the training, but they attended the training. Out of the 5 nurses, one resigned her position and was not available for the final assessment.

The male: female ratio was 13:17 for doctors and 11:29 for nurses. Professional experience was variable (average 70 months, minimum 8 and maximum 300 months).
The mean experience of work in the emergency department was: 149 months (minimum 72 and maximum 300 months) for the EM attendings, 30 months (minimum 12, maximum 52 months) for the residents and 38 months (minimum 8 and maximum 156 months) for nurses.

Collected data were analyzed separately for doctors and nurses. Results are reported in Table I and Table II.

In general, doctors were satisfied with the current work situation, for most of the items evaluated median being 5 or 6 , before and after training. The worst aspects according to their rating were the workload (median 2), the leisure time (median 3), the level of stress at work (median 3 ), the time and the energy spent on administrative tasks (median 3). An improvement was seen after the training for the level of stress at work (median 4.5) and time spent on administrative work (median 4), but significance level was not reached. A significant change in a positive way was noticed on the possibility to refer the patients to a specialist if necessary $(\mathrm{p}=0,025)$.

According to their rating, nurses were also satisfied with their work situation, for most of the elements median being 5 or 6 and the training didn't change significantly their perception. The lowest score was given for the workload (median 4) and the highest one (7) was given for the opportunities for continuing medical education.

\section{Discussions}

Work satisfaction is a complex variable and one of the most researched within the field of occupational and organizational psychology. It has been defined as 'a measure of workers' contentedness with their job, whether or not they like the job or individual aspects or facets of jobs, such as nature of work or supervision.' [17] People's attitudes towards their work life influence the quantity and quality of work that individuals will develop as well as other variables

Table I. Results of the work satisfaction questionnaire for physician

\begin{tabular}{|c|c|c|c|c|c|c|}
\hline & \multirow{2}{*}{ Element } & \multicolumn{2}{|c|}{ Initial assessment } & \multicolumn{2}{|c|}{$\begin{array}{c}\text { Final } \\
\text { assessment }\end{array}$} & \multirow[t]{2}{*}{ P value* } \\
\hline & & Median & IQR & Median & IQR & \\
\hline \multirow{4}{*}{ Patient care } & Your relations with your patients & 5 & 2 & 5 & 1 & 0.739 \\
\hline & The possibility to treat your patients as you see it & 5.5 & 2 & 6 & 1.75 & 0.390 \\
\hline & $\begin{array}{l}\text { The possibility to refer your patients to a specialist whenever } \\
\text { you think is necessary }\end{array}$ & 4 & 2.25 & 5 & 3 & 0.025 \\
\hline & The quality of care you are able to provide & 6 & 1 & 6 & 0.75 & 0.928 \\
\hline \multirow{4}{*}{ Burden } & Your workload & 2 & 3 & 2 & 3.75 & 0.290 \\
\hline & The time you have for family, friends or leisure activities & 3 & 1 & 3 & 2 & 0.322 \\
\hline & The level of stress you experience at work & 3 & 3 & 4.5 & 3 & 0.435 \\
\hline & The time and energy you spend on administrative tasks & 3 & 2.25 & 4 & 2 & 0.448 \\
\hline \multirow{2}{*}{ Income-prestige } & Your current income & 4.5 & 2.25 & 5 & 2 & 0.253 \\
\hline & Your social status and the respect people show you & 5 & 2.25 & 5 & 3 & 0.907 \\
\hline \multirow{3}{*}{ Personal rewards } & Your intellectual stimulation at work & 5.5 & 1.25 & 5 & 2 & 0.524 \\
\hline & Your opportunities for continuing medical education & 6 & 2 & 6 & 2 & 0.598 \\
\hline & Your enjoyment at work & 5 & 2.25 & 5 & 1.75 & 0.242 \\
\hline \multirow{3}{*}{ Professional relations } & $\begin{array}{l}\text { Your professional relations and interactions with medical doc- } \\
\text { tors from your department }\end{array}$ & 6 & 0.25 & 6 & 1 & 0.146 \\
\hline & $\begin{array}{l}\text { Your professional relations and interactions with medical doc- } \\
\text { tors from other specialties }\end{array}$ & 5 & 1.25 & 5 & 1.75 & 0.884 \\
\hline & Your relations with non-medical staff (nurse, assistant) & 6 & 1.25 & 6 & 2 & 0.213 \\
\hline General item & All things considered, your professional situation at this time & 5 & 1.25 & 5 & 1 & 0.306 \\
\hline
\end{tabular}


Table II. Results of the work satisfaction questionnaire for nurses

\begin{tabular}{|c|c|c|c|c|c|c|}
\hline & \multirow[b]{2}{*}{ Element } & \multicolumn{2}{|c|}{ Initial assessment } & \multicolumn{2}{|c|}{$\begin{array}{l}\text { Final } \\
\text { assessment }\end{array}$} & \multirow[t]{2}{*}{ P value* } \\
\hline & & Median & IQR & Median & IQR & \\
\hline \multirow{3}{*}{ Patient care } & Your relations with your patients & 6 & 1 & 5 & 1 & 0.305 \\
\hline & $\begin{array}{c}\text { The possibility to refer your patients to a specialist whenever you } \\
\text { think is necessary }\end{array}$ & 5 & 2.5 & 5 & 2 & 0.477 \\
\hline & The quality of care you are able to provide & 6 & 2 & 6 & 1 & 0.183 \\
\hline \multirow{3}{*}{ Burden } & The time you have for family, friends or leisure activities & 5 & 3 & 4 & 2 & 0.642 \\
\hline & The level of stress you experience at work & 5 & 2 & 4 & 3 & 0.398 \\
\hline & The time and energy you spend on administrative tasks & 5 & 2 & 5 & 1 & 0.340 \\
\hline \multirow{2}{*}{ Income-prestige } & Your current income & 5 & 2 & 4 & 3 & 0.103 \\
\hline & Your social status and the respect people show you & 6 & 1 & 6 & 1 & 0.521 \\
\hline \multirow[b]{2}{*}{ Personal rewards } & Your intellectual stimulation at work & 6 & 1.5 & 6 & 1 & 0.955 \\
\hline & Your opportunities for continuing medical education & 7 & 1 & 7 & 1 & 0.802 \\
\hline \multirow{3}{*}{ Professional relations } & $\begin{array}{c}\text { Your professional relations and interactions with medical doctors from } \\
\text { your department }\end{array}$ & 6 & 2 & 6 & 1 & 0.713 \\
\hline & $\begin{array}{c}\text { Your professional relations and interactions with medical doctors from } \\
\text { other specialties }\end{array}$ & 6 & 1.5 & 5 & 2 & 0.677 \\
\hline & Your relations with non-medical staff (nurse, assistant) & 6 & 1 & 6 & 1 & 0.571 \\
\hline General item & All things considered, your professional situation at this time & 5 & 1 & 6 & 1 & 0.308 \\
\hline
\end{tabular}

*Wilcoxon test

such as absenteeism, tendency to leave the organization, and high rotation rates [18].It seems to be impacted by an increasing number of factors, both intrinsic and extrinsic, such as conflict, compensation and pay, workload, interpersonal relationships, career development, information access and feedback [19].

Very few data connecting CRM training and job satisfaction are available in the literature. To our knowledge, this is the first study that assesses the effects of a CRM oriented training performed in a safe and friendly environment (the simulation center) on the perception of overall work satisfaction among Emergency Department medical staff in Romania.

Work satisfaction was measured through a questionnaire that has five specific domains and a general one.

\section{Patient Care}

This topic refers mostly to the complex interactions between physician, patient and the healthcare system. CRM training provided during this study covered only a very small portion of this topic, as it was intended to improve team dynamics in emergency and time pressured situations. ED team members were trained to adopt behaviors that would prevent human errors and thus ensure higher levels of patient safety during acute care, such as being aware of the possible dangers and communicating them assertively regarding their hierarchical status, exercising leadership and fellowship, mobilizing all the available resources, preventing and managing fixation errors, distributing the workload etc. The only significant change $(\mathrm{p}=0.025)$ seen after the training, and only for the physicians, regards the possibility to refer the patient to a specialist when considered necessary. This result is difficult to interpret in the context of CRM training. We are not sure whether their answer is reflecting one of the principles taught during the training, namely "calling for help early", as this should be applied to difficult situations when quick help is necessary or is referring to the possibility to admit or to send the patient to another specialist doctor. If the second possibility is the real one, the lack of change for the same item in the case of nurses is not surprising, as disposition is not their responsibility. Even more, some studies found that dissatisfied physicians used more total outpatient procedures and made more referrals than physicians who are satisfied. $[5,20]$ As shown by Boet et al. in a systematic review, there are few studies that followed and demonstrated the transfer of CRM skills learned to clinical settings and even less on patient's outcome improvement [21]. Little is known about the impact of these skills on healthcare providerpatient interactions and the overall patient care.

\section{Burden}

The lowest scores were given by both professional categories, physicians and nurses before and after the training for the workload and 'time to spend with the family, friends or for leisure activities'. These findings are in accordance with the existing literature on the subject, both of them being reasons for work dissatisfaction and for the intention to leave, among physicians and nurses working in EDs $[5,22]$. Morey et al, showed a significant decrease in error rate and an improvement in staff attitude through a teamwork-oriented training, but no difference was found in the subjective workload experience [14]. The lack of personnel and the elevated healthcare work burden are among the reasons that explain it. Strategies to improve these aspects are necessary. According to Suarez et al, rotation between different acuity levels in the ED seems to play a protective role against job dissatisfaction [22]. However, in the physician's group an improvement was noticed on the 'level of stress at work' and 'time and energy spent on administrative 
tasks'. These might have been influenced by CRM training. Complex, rapidly evolving or unfamiliar emergency cases can be extremely stressful events for members of the ED. Principles such as: know your environment, anticipate, share, communicate effectively, call for help, distribute the workload are emphasized during the CRM training and could have played a role. Kaissi et al, demonstrated that effective teamwork can lead to increased control over the work environment in hospital high-risk areas: emergency department, intensive care unit, operating theatre. This control was reflected in an increase of effectiveness, time efficiency, staff morale and patient satisfaction, as well as lower stress for staff and patients [23].

\section{Income-Prestige}

Concerning salary and prestige, there were no statistically significant differences, which is not surprising, as these elements couldn't be directly influenced by the training.

\section{Personal rewards}

No statistically significant changes were noted in this domain, although findings across literature suggest that simulation-based training may serve as an enjoyable, applicable, and realistic tool to enhance a team's performance across all caregivers and different levels of experience. [24]. According to their scores, our participants were quite satisfied with these aspects even before training, particularly with 'opportunities for continuing medical education' (median 6 for doctors and 7 for nurses). This might be explained by the easy access of the staff working in this specific ED, to different courses that are organized in the simulation center.

\section{Professional relations}

The importance of interpersonal relationships at work as a protective factor against stress and professional burnout has been reported previously $[21,25]$.

Although CRM training emphasized the importance of: communication management, reducing the interference of personal problems, reducing the power discrepancy between those in authority and subordinates, debriefing after a case and team building, which could have led to an increase in interactions with peers, no statistically significant changes were noted in our study in professional relations neither inside or outside the department. However, the initial scores were rated quite high (medians of 6 and 5). So, these results were partially expected. Out of 136 ED medical staff members, 110 were exposed to CRM training during the study period or before, with $19 \%$ of the clinical staff remaining untrained with regards to teamwork principles. This could lead to a restrain in implementing the acquired knowledge in the work environment, while favoring the 'traditional' way of working and communicating. There is also a high rate of staff renewing, which requires time to integrate new members into a team and to operate at high standards. Also, the duration of the CRM train- ing might be insufficient to change attitudes and behaviors that have been formed and consolidated over the years. Increasing the length of the training or periodically repeating the simulation session might increase its effect.

\section{General score of satisfaction}

The general level of satisfaction did not seem to be influenced by the training in the case of physicians and only slightly improved in the case of nurses. This is in accordance with a similar study conducted by Meurling et all in 2013 in Sweden, on 151 ICU staff members (physicians, nurses and nurse assistants). Comparable to our study, the ICU staff was exposed to 1 day of training including 5 standardized scenarios, with structured debriefing aimed at clinical performance and CRM based behavior targets. Job satisfaction was a secondary objective of their study. The results showed an improvement of self-efficacy scores for nurses and physicians as well as of the perceived quality of collaboration and communication with other physicians after the training. Teamwork, safety climate and working conditions were perceived more positive at the end of the study, by nurse assistants. The number of nurses quitting their job and the time of sick leave for nurses decreased from $28 \%$ to $12 \%$ during the study period (2006-2010) [26]. Interestingly, however was that job satisfaction scores did not change and even showed a slight decrease for the nurse category.

\section{Limitations}

This study has several limitations. Despite the high percentage of participation, not all the professionals in the ED were included. This fact may have influenced some of the results. For the purpose of our study we used a validated job satisfaction questionnaire which was developed based on the main components of work satisfaction identified by qualitative research of the Society of General Internal Medicine Career Satisfaction Study Group. This tool was validated on a group of 1184 physicians, members of the Geneva Medical Association. They have different specialties and most of them were working in the private sector and were paid on a fee-for-service basis [15]. The context and the target group for which this tool was validated are different that those in our study. Medical practice in the ED has unique characteristics in the healthcare system which make it more prone to notable physical and mental distress of the healthcare workers, to burnout and to work dissatisfaction [27]. In our hospital the work is delivered in a state sector and involves frequent overcrowding, scarcity of resources, a generally stressful and sometimes even hostile setting. However, to our knowledge nowadays there is no concise and pragmatic instrument that follows a framework for validity specifically designed for measuring work satisfaction among ED's staff. The correlation with preexisting literature was limited by scarce studies sharing the same interest. Another weakness might be the lack of an evaluation immediately after the training, due to limited 
resources. We don't know if during these two months the effect of the training faded or improved.

\section{Conclusions}

While reports in literature show that simulation-based training which includes CRM principles can improve elements associated directly or indirectly with work satisfaction (teamwork, communication, sickness absenteeism), the findings of our study are not supporting the effectiveness of CRM training on work satisfaction among ED medical staff.

Further studies are needed to confirm whether familiarizing emergency medical staff with the concepts of efficient teamwork in difficult situations, all under the safety conditions provided by a simulation center, could influence some aspects of work satisfaction, such as the quality of care provided to patients, intra and inter-professional relationships, stress management at work and intellectual stimulation.

Developing a specific questionnaire dedicated and validated for the study target group, including the whole ED's staff and expanding the duration of the training would be necessary.

\section{Authors' contribution}

TST - Conceptualization, investigation, methodology, writing original draft

IB - Investigation, writing - original draft

$\mathrm{CB}-$ Methodology, supervision, validation, writing review and editing

MP - Formal analysis, validation, writing review and editing

DAM - Investigation, validation, writing review and editing

SMC - Data curation, supervision, validation, writing review and editing

\section{Conflict of interest}

Non to declare.

\section{References}

1. Lu DW, Dresden S, McCloskey C, et al- Impact of Burnout on SelfReported Patient Care Among Emergency Physicians. West J Emerg Med. 2015;7:996-1001.

2. Ionita A, Copotoiu M, Pascan C, et al- Assessment of occupational stress in some medical and surgical specialties. Acta Med Marisiensis. 2011;57(3):214-7.

3. Cydulka RK, Korte R- Career satisfaction in emergency medicine: the ABEM Longitudinal Study of emergency Physicians. Ann Emerg Med. 2008;51(6):714-22.

4. Wada K, Aritmasu M, Yoshikawa T, et al- Factors on working conditions and prolonged fatigue among phycisian in Japan. Int Arch Occup Environ Health. 2008;82(1):59-66.

5. Chan TN, Tung WK, Man KH- Emergency physician job satisfaction in Hong Kong. Hong Kong j emerg med. 2014;21(5):273-82.

6. Hass JS, Cook EF, Puopolo AL, Burstin HR, et al- Is the professional satisfaction of general internists associated with patient satisfaction? J Gen Intern Med. 2000;15:122-8.

7. Ten Eyck R, Tews M, Ballester J- Improved medical student satisfaction and test performance with a simulation-based emergency medicine curriculum: a randomized controlled trial. Ann Emerg Med. 2009;54(5):684-91.

8. Waterman AD, Garbutt J, Hazel E et al- The Emotional Impact of Medical Errors on Practicing Physicians in the United States and Canada. Jt Comm J Qual Patient Saf. 2007;33(8):467-76.

9. Lee D, Lee SM, Schniederjans MJ- Medical error reduction: the effect of employee satisfaction with organizational support. Serv Ind J. 2011;31(8):1311-25

10. Bolandianbafghi S, Salimi T, Rassouli M, et al- Correlation between medication errors with job satisfaction and fatigue of nurses. Electron Physician. 2017 Aug;9(8):5142-8. doi: 10.19082/5142

11. Bleetman A, Sanusi S, Dale T, et al- Human factors and error prevention in emergency medicine. Emerg Med J. 2012;29:389-93.

12. Petrosoniak A, Hicks CM- Beyond crisis resource management: new frontiers in human factors training for acute care medicine. Curr Opin Anesthesiol.2013;26:699-706.

13. Rall M, Gaba D- Human Performance and Patient Safety. In Miller RD (ed): Miller ?s Anesthesia, Philadelphia, Elsevier Churchill Livingstone. 2005, 3021-72.

14. Morey JC, Simon R, Jay GD, et al- Error reduction and performance improvement in the emergency department through formal teamwork training: evaluation results of the MedTeams project. Health Serv Res.2002;37:1553-81.

15. Bovier AP, Perneger VT- Predictors of work satisfaction among physicians. European Journal of Public Health.2003;13:299-305.

16. Carne B, Kennedy M, Gray T-Review article: Crisis resource management in emergency medicine. Emerg Med Australas. 2012;24:7-13.

17. Paul SE- Job Satisfaction:Application, Assessment, Causes and Consequences 1997. Doi:http://dx.doi.org/10.4135.

18. George JM, Jones GR- Organisational behaviour. 3rd ed. Prentice Hall: New Jersey. 2002.

19. Trivellasa P, Reklitisa P, Platisb C- The effect of job related stress on employees' satisfaction: A survey in Health Care. Procedia - Social and Behavioral Sciences 2013;73:718 -26.

20. Eisenberg JM- Doctors 'decisions and the Cost of Medical Care. The Resons for Doctors' Practice Patterns and Ways to Change Them. Ann Arbor, Ml: Health Administration Press;1986.

21. Boet $S$, Bould MD, Fung $L$, et al- Transfer of learning and patient outcome in simulated crisis resource management: a systematic review. Can J Anesth 2014;61:571-82.

22. Suárez $M$, Asenjo $M$, Sanchez $M$, et al- Job satisfaction among emergency department staff. Australas Emerg Nurs J 2017;20:31-36.

23. Kaissi A, Johnos T, Kirschbaum MS- Measuring Teamwork and patient safety attitudes of hidh-risk areas. Nurs Econ 2003;21(5):211-8.

24. Heard LA, Perceptions of simulation-based training in crisis resource management in the endoscopy unit. Gastroenterol Nurs. 2011;34(1):428.

25. Tourangeau AE, Cummings G, Cranley LA, et al- Determinants of hospital nurse intention to remain employed: broadening our understanding. J Adv Nurs 2010;66:22-32.

26. Meurling L, Hedman L, Sandhal C,et al- Systematic simulation-based team training in a Swedish intensive care unit: a diverse response among critical care professions. BMJ Qual Saf 2013;22:485-94.

27. Timmel J, Kent PS, Holzmueller CG et al- Impact of the comprehensive unit-based safety program (CUSP) on safety culture in a surgical inpatient unit. Jt Comm J Qual Patient Saf 2010;36:252-60. 